\title{
Removal of humic acid from peat water using untreated powdered eggshell as a low cost adsorbent
}

\author{
M. A. Zulfikar • E. Novita • \\ R. Hertadi $\cdot$ S. D. Djajanti
}

Received: 1 January 2012/Revised: 3 January 2013/ Accepted: 2 February 2013/Published online: 22 February 2013

(C) Islamic Azad University (IAU) 2013

\begin{abstract}
The main objective of this study is to investigate the possibility of powdered eggshell used as an adsorbent material for removal of humic acid from peat water. The influences of contact time, dose of eggshells, $\mathrm{pH}$, and temperature were the factors considered in the removal processes of humic acid from peat water. In addition, adsorption isotherms of humic acid onto the powdered eggshell were also evaluated with the Langmuir and Freundlich approximations. Our results showed that the equilibrium of the process was eventually established after $60 \mathrm{~min}$ of the contact time, and also found that using $5 \mathrm{~g}$ of the powdered eggshell nearly $95 \%$ of humic acid has been successfully removed from the peat water. The removal of humic acid gave better result when it was conducted at low $\mathrm{pH}$, and it was almost unaffected the temperatures variation. The data was well fitted to Freundlich isotherm with the correlation coefficient of not $<0.999$, and could uptake the humic acid about $126.58 \mathrm{mg} / \mathrm{g}$ at $\mathrm{pH}$ 4.01, estimated from the Langmuir model. The kinetic experimental data proportionally correlated with the pseudo-second-order kinetic model with a rate constant in the range of $0.016-0.112 \mathrm{~g} \mathrm{mg}^{-1} \mathrm{~min}^{-1}$, while intra-particle-diffusion were the main rate determining step in the
\end{abstract}

M. A. Zulfikar $(\bowtie) \cdot$ S. D. Djajanti

Analytical Chemistry Research Group, Institut Teknologi

Bandung, Jl. Ganesha 10, Bandung 40132, Indonesia

e-mail: zulfikar@chem.itb.ac.id

E. Novita

Madrasah Aliyah Negeri 2 Pekanbaru, Jl. Pangeran

Diponegoro 55, Pekanbaru 28131, Indonesia

R. Hertadi

Biochemistry Research Group, Institut Teknologi

Bandung, Jl. Ganesha 10, Bandung 40132, Indonesia humic acid removal process. The powdered eggshell investigated in this study, thus, exhibited as a high potential adsorbent for the removal of humic acid from peat water.

Keywords Adsorption - Calcium carbonate - Isotherm · Kinetics

\section{Introduction}

One of problems that are faced by people who live in lowland and marshy area is the scarcity of available clean water. This is due to the fact that the abundant source of water in that area is peat water. Such problem is also readily found in several remote villages in Riau Province, Indonesia. Almost $45 \%$ of Riau Province area is peat land; thereby, the major source of water is peat water. Peat water is water having more than $75 \%$ organic content with red brown color and has the character of acid.

Humic acid is one of the main components of peat water that consisted of large molecules with molecular weights ranging from thousands to hundreds of thousands (Gezici et al. 2005) and have a backbone of aromatic and aliphatic residues with numerous substituents such as $\mathrm{OH}$ groups, ketones, carboxylic acid groups, amino acids/peptides, saccharides, and amino saccharides (Albers et al. 2008). Humic acid imparts a brown or yellow color in peat water and pose a serious environmental problem, particularly in drinking water treatment because of their taste and odor. They also tend to react with a variety of oxidants and disinfectants used for the purification of drinking water forming carcinogenic disinfection byproducts (DBPs) such as trihalomethanes and haloacetic acids (Daifullah et al. 2004; Kamari et al. 2009; Ngah et al. 2011; Uygunera et al. 2007; Sonea et al. 2010; Tao et al. 2010; Wang et al. 2008a; Wang et al. 2011). 
In order to acquire clean water from peat water, it is necessary to do pretreatment process to this water. At present, there are several methods used to remove humic substance, especially humic acid as main component from peat water, such as coagulation-flocculation (Uygunera et al. 2007), electro coagulation processes (Ghernaout et al. 2009), oxidation (Uygunera et al. 2007), photocatalysis (Sonea et al. 2010), and membrane technology (Katsoufidou et al. 2010). All of these alternative processes, however, are high operational cost, especially when applying membrane technology, because humic acid component tends to severely foul the membrane (Katsoufidou et al. 2010) and hence, limiting the membrane application in this field. None of them, therefore, is considered by industries to be commercially viable because economically unrealistic.

Being easy to operate and being the most effective, adsorption has been considered as one of the most economically promising techniques for the water and wastewater treatments (Gupta et al. 2009). Activated carbon is the most widely studied and used adsorbents for water and wastewater treatments (Gupta et al. 2009). However, the main disadvantage of activated carbon is its high cost in manufacturing and treatment and difficult to regenerate. Therefore, there is a need to continue the search and developing alternative adsorbents with high adsorptive capacity and low cost for humic acid removal. As a consequence, numerous low cost materials such as rice husk activated carbon (Daifullah et al. 2004), Shorea dasyphylla sawdust (Kamari et al. 2009), chitosan (Wang et al. 2008a), fly ash (Wang et al. 2008b), and other adsorbents (Ngah et al. 2011; Sonea et al. 2010; Tao et al. 2010; Wang et al. 2011; García et al. 1998; Zhang and Bai 2003; Ngah et al. 2008) were used for removal of humic acid. In the present work, the possibility of powdered eggshell to be used as an adsorbent material for removal of humic acid from peat water has been investigated. The choice of eggshell as the adsorbent is due to its reasonable cost and ease of regeneration. In addition, there is no study reported in the literature related to the use of powdered eggshell as an adsorbent to removal of humic acid from peat water to produce clean water. In this study, the effect of contact time, adsorbent dosage, $\mathrm{pH}$, and temperature on the adsorption were investigated. Adsorption isotherm model and kinetic models were also investigated. This work was done in 2010, at Chemistry Department of Bandung Institute of Technology, Indonesia.

\section{Materials and methods}

Adsorbent preparation

Chicken eggshells collected from Balubur traditional market Bandung was initially washed with detergent and the membrane layer was manually separated from the shells. The membrane free eggshell was further washed with distilled water, and then air-dried for 2 days before it was finally grounded to $75 \mu \mathrm{m}$ in particle size.

Peatwater solution preparation

The peat water sample was obtained from Bukit Timah, a sub district of Dumai city in Riau Province, Indonesia. Before mixing the peat water sample with adsorbent, its $\mathrm{pH}$ value was adjusted using $\mathrm{NaOH}$ and $\mathrm{HCl}$ (Merck, Germany) with $0.1 \mathrm{M}$ in concentration. The $\mathrm{pH}$ value was measured using 300 Hanna Instrument (USA) pH meter. The characteristic of peat water sample can be seen at Table 1.

Characterization of powdered eggshells

In order to examine the crystallinity of the powdered eggshells, X-ray diffraction of sample were recorded using RINT 2000 (Rigaku Instrument Corp., Japan) with $\mathrm{Cu} \mathrm{Ka}$ radiation. A scanning electron microscope (JEM-2010, JEOL, Japan) was used for the investigation of particle morphology of powdered eggshells. Fourier transform infra red spectroscopic model 8300 IR-TF (Shimadzu, Japan) analysis was performed within the range $400-4,000 \mathrm{~cm}^{-1}$ to identify the presence of functional groups in the samples. The zeta potential of eggshells as a function of $\mathrm{pH}$ in $0.01 \mathrm{~mol} / \mathrm{L}$ sodium chloride was measured using a ZetaPlus 4 Instrument (Brookhaven Instruments Corp., USA). The surface area of powdered eggshells was analyzed through nitrogen adsorption measurements at $77 \mathrm{~K}$ using Micromeritics Gemini 2370 (USA) equipment.

Batch adsorption studies

Adsorption experiments were carried out by mixing of 1,3 and $5 \mathrm{~g}$ chicken eggshell with $50 \mathrm{~mL}$ peat water $\mathrm{pH}$ of 4.01 at $25{ }^{\circ} \mathrm{C}$ in thermostatic shaker bath (Innova 3000, 3000)

Table 1 The peat water sample characteristics

\begin{tabular}{lll}
\hline Parameters & Unit & Result \\
\hline Color & $\mathrm{Pt}-\mathrm{Co}$ & 475 \\
Organic compounds & $\mathrm{mg} / \mathrm{L} \mathrm{KMnO}_{4}$ & 238 \\
$\mathrm{pH}$ & - & 4.01 \\
Conductivity & $\mu \mathrm{S} / \mathrm{cm}$ & 62 \\
Turbidity & $\mathrm{mg} / \mathrm{L} \mathrm{SiO}{ }_{2}$ & 7.5 \\
Iron & $\mathrm{mg} / \mathrm{L}$ & 0 \\
Manganese & $\mathrm{mg} / \mathrm{L}$ & 0 \\
Calcium & $\mathrm{mg} / \mathrm{L}$ & 0 \\
Magnesium & $\mathrm{mg} / \mathrm{L}$ & 6.2 \\
\hline
\end{tabular}


with shaking speed at $100 \mathrm{rpm}$ for $2,5,10,15,20,25,30$, $45,60,75,120,180,240$ and $300 \mathrm{~min}$. At the end of the predetermined time interval, the suspension was taken out and the supernatant was centrifugated. The concentration of humic acid solution was measured by an ultravioletvisible spectrophotometer model UV-vis 1601 (Shimadzu, Japan) at the $\lambda 400 \mathrm{~nm}$ (Zhang and Bai 2003). As the absorbance was $\mathrm{pH}$-dependent, calibration lines were made for each required $\mathrm{pH}$ in the study. The percent of humic acid removal from peat water was calculated using the following equation:

Removal $(\%)=\frac{C_{i}-C_{e}}{C_{i}} \times 100$

where $C_{i}$ and $C_{e}$ are initial and final concentration of humic acid $(\mathrm{mg} / \mathrm{L})$ in solution, respectively. The adsorption capacity of an adsorbent at equilibrium with solution volume $V$ was calculated using the following equation:

$q_{e}(\mathrm{mg} / \mathrm{g})=\frac{C_{i}-C_{e}}{m} \times V$

where $C_{i}$ and $C_{e}$ are the initial and final concentration of humic acid $(\mathrm{mg} / \mathrm{L})$ in solution, respectively. $V$ is the volume of solution (L) and $m$ is mass of adsorbent $(\mathrm{g})$ used.

The effect of $\mathrm{pH}$ on the humic acid removal from peat water was studied in the suspension with $\mathrm{pH}$ range from 2.0 to 10.0 by adjusting the $\mathrm{pH}$ using $0.1 \mathrm{M} \mathrm{HCl}$ and $0.1 \mathrm{M} \mathrm{NaOH}$ solution and using $3 \mathrm{~g}$ of powdered eggshell for $15,30,45,60$, 75 , and 90 min at $25{ }^{\circ} \mathrm{C}$ and shaking speed at $100 \mathrm{rpm}$.

The effect of dosage of powdered eggshell on the humic acid removal was investigated by mixing $50 \mathrm{~mL}$ peat water with different dosages $(1,3,5,7,10,15$ and $20 \mathrm{~g})$ for $60 \mathrm{~min}$ and at $\mathrm{pH}$ of $4.01,25{ }^{\circ} \mathrm{C}$ and shaking speed at $100 \mathrm{rpm}$. To analyze the effect of temperature on humic acid removal, the experiments were carried out at different temperatures: $25,45,55$ and $65^{\circ} \mathrm{C}$. The amount of powdered eggshells used was $3 \mathrm{~g}$ in $50 \mathrm{~mL}$ of peat water sample at $\mathrm{pH} 4.01$ with shaking speed at $100 \mathrm{rpm}$.

For desorption studies, $5 \mathrm{~g}$ of powdered eggshell were loaded with $50 \mathrm{~mL}$ peat water at $\mathrm{pH} 7$ and $25{ }^{\circ} \mathrm{C}$ for $30 \mathrm{~min}$. The loaded powdered eggshell collected was gently washed with distilled water to remove any unabsorbed humic acid. The powdered eggshell was then loaded with $50 \mathrm{~mL}$ of $\mathrm{HCl}$ at concentration $0.1-0.001 \mathrm{M}$ for $120 \mathrm{~min}$. The desorption percentage (DP) of humic acid is defined as (Ngah et al. 2008):

$D P=\frac{C_{e(d e s)}}{C_{e(a d s)}} \times 100 \%$

Study of adsorption isotherm

Adsorption experiments were carried out by mixing various dosage of powdered eggshell $(1,3,5,7,10,15$ and $20 \mathrm{~g})$ with $50 \mathrm{ml}$ of peat water sample, which other conditions were held constant at $\mathrm{pH}$ of 4.01 , particle size of $75 \mu \mathrm{m}$, and temperature of $25^{\circ} \mathrm{C}$. The experimental data were calculated to determine the adsorption isotherm using the Langmuir and Freundlich models.

\section{Results and discussion}

Characterization of powdered eggshells

From the XRD patterns (Figure not shown), it was found that the eggshell structure is similar to the calcite structure containing calcium carbonate mineral (Murakami and Rodrigues 2007). The surface morphology of the eggshell sample, which analyzed with SEM, showed that it has many pores with different sizes and shapes (Fig. 1). SEM image was also revealed that the eggshells have crystalline structure, exhibited an angular pattern (Tsai et al. 2006), non-adhesive appearance, and formation of agglomerates. This observation was similar to other researches reported (Bhaumik et al. 2012).

The zeta potential of eggshells as a function of the $\mathrm{pH}$ solution values are shown in Fig. 2. The zeta potentials are positive in an acidic condition but negative in a basic condition. The point of zero zeta potential was obtained at about $\mathrm{pH} 8.8$ which is similar to the zero zeta potential of calcite reported by other (Labidi and Djebaili 2008). Below $\mathrm{pH} 8.8$, the zeta potential of eggshells increases with the decrease of solution $\mathrm{pH}$ value. This may be attributed to the $\mathrm{Ca}^{2+}$ and $\mathrm{CaOH}_{2}^{+}$species adsorbed at eggshell surface. Above $\mathrm{pH} 8.8$, the zeta potential of eggshell was negative, because of excess $\mathrm{HCO}_{3}{ }^{-}$and $\mathrm{CO}_{3}{ }^{2-}$ species adsorbed at its surface (Bhaumik et al. 2012).

IR spectra of the powdered eggshells before adsorption showed that the most significant peak of intensity of powdered eggshells is at $1425.40 \mathrm{~cm}^{-1}$ (Fig. 3); thereby, strongly associated with the presence of carbonate minerals

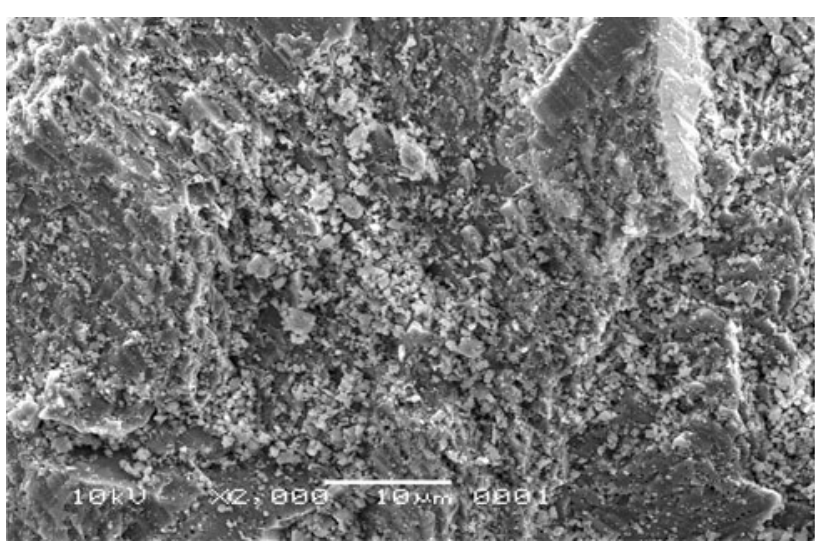

Fig. 1 SEM micrographs of powdered eggshell 


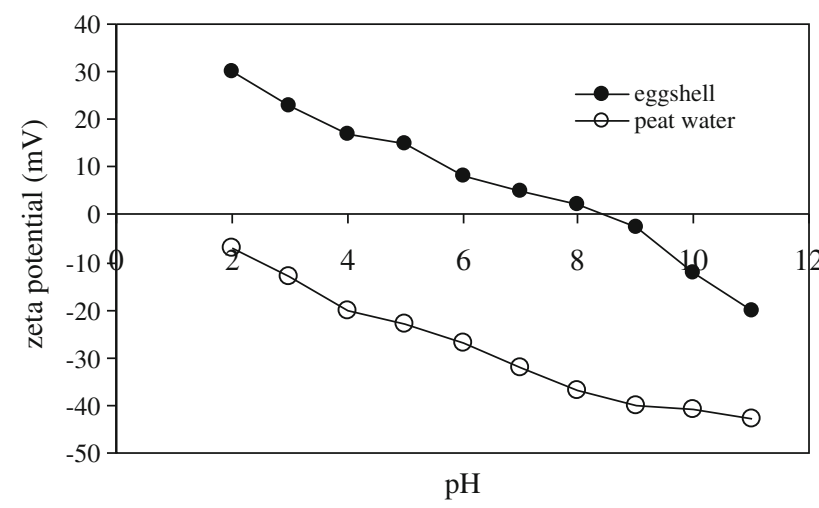

Fig. 2 Zeta potential of powdered eggshell

within the eggshells matrix (Tsai et al. 2006; Carvalho et al. 2011). There are also two observable peaks at about 711.73 and $875.68 \mathrm{~cm}^{-1}$ which should be associated with the in-plane deformation and out-plane deformation modes, respectively, in the presence of calcium carbonate (Tsai et al. 2006; Carvalho et al. 2011).

The surface area of powdered eggshells obtained from nitrogen adsorption measurement is $3.23 \mathrm{~m}^{2} / \mathrm{g}$. This value is greater than that obtained by Tsai et al. (2006), but smaller than that obtained by Kose and Kivanc (2011).

\section{Effect of contact time}

Figure 4 shows the effect of contact time on humic acid removal from peat water on powdered eggshell for different dosages. Based on the plot, humic acid removal was relatively fast with more than $50 \%$ of peat water removed in $<15 \mathrm{~min}$. This was due to the increased availability of adsorption site for the uptake of humic acid. Meanwhile, the second slower phase was due to the quick exhaustion of

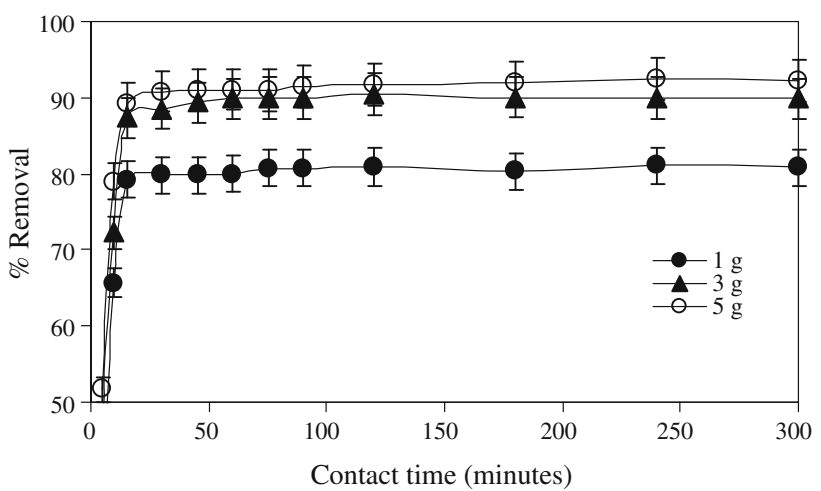

Fig. 4 Effect of contact time on humic acid removal from peat water onto powdered eggshell (volume $50 \mathrm{~mL}, \mathrm{pH} 4.01$, particle size $75 \mu \mathrm{m}$, shaking speed $100 \mathrm{rpm}$, and $25^{\circ} \mathrm{C}$ )

the adsorption sites (Ngah et al. 2011). The adsorption rapidly occurs and normally controlled by the diffusion process from the bulk to the adsorbent surface (Bhaumik et al. 2012). After $60 \mathrm{~min}$, it can be observed that the humic acid removal remained constant, indicating the establishment of equilibrium

\section{Effect of powdered eggshells dosage}

The effect of powdered eggshell dosages on humic acid removal was shown in Fig. 5. The maximum humic acid removal of about $94.56 \%$ was observed at the dosage of $5 \mathrm{~g}$. The percentage removal decreased slightly at higher dosage (up to $5 \mathrm{~g}$ ) of the adsorbent. This trend could be explained as a consequence of partial aggregation, agglomeration, overlapping, and overcrowding of adsorbent at higher dosage; thereby, reducing the availability of surface area for adsorption (Bhaumik et al. 2012;
Fig. 3 Infra red spectrum of powdered eggshell

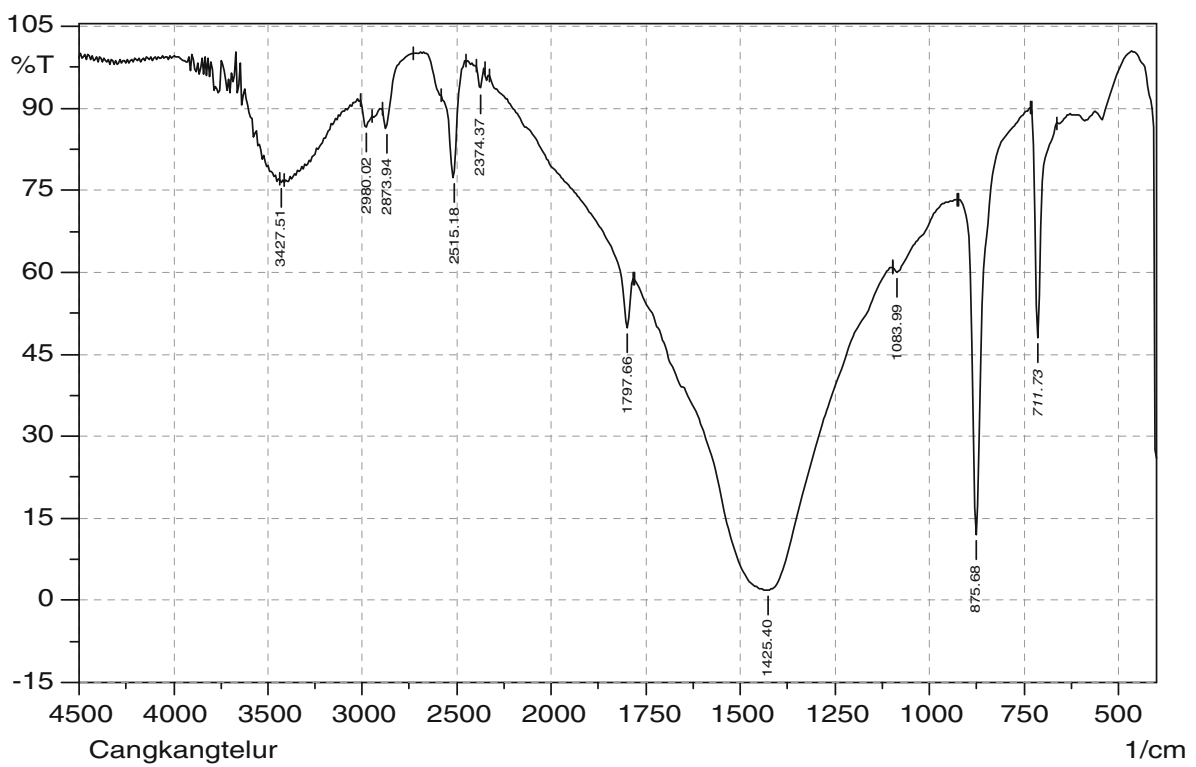




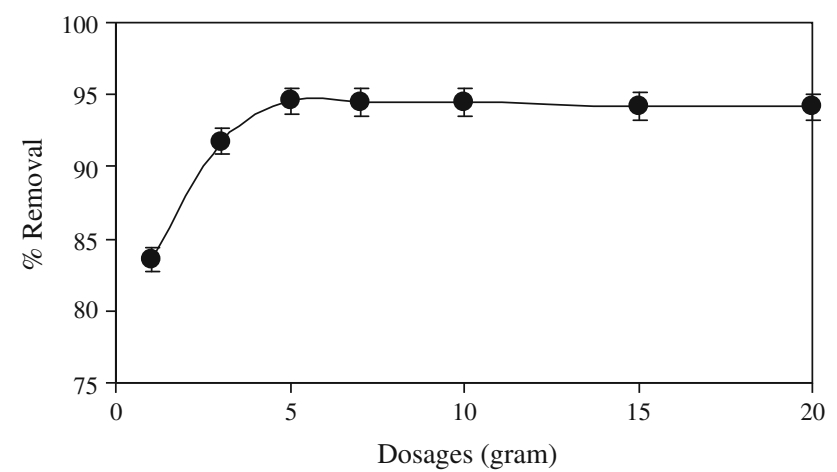

Fig. 5 Effect of dosages on humic acid removal from peat water onto

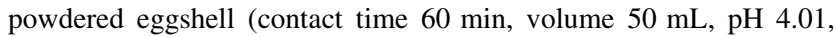
particle size $75 \mu \mathrm{m}$, shaking speed $100 \mathrm{rpm}$, and $25^{\circ} \mathrm{C}$ )

Elwakeel and Yousif 2010; Gupta and Rastogi 2008; Ehrampoush et al. 2011).

\section{Effect of $\mathrm{pH}$}

The effect of $\mathrm{pH}$ on humic acid removal from peat water by powdered eggshells (Fig. 6) demonstrated that the optimum humic acid removal from peat water occurred at $\mathrm{pH}$ 2 , and it would decreases when increasing the $\mathrm{pH}$ value of the initial solution.

To explain the adsorption behavior of this humic acid, a model of modified double-electric layer has been used (Zulfikar et al. 2012). According to this model, the Stern layer consists of two layers: an inner layer (IL) in which adsorbed molecules or ions connect with surface of eggshell directly and an outer layer (OL) in which adsorbed molecules or ions have a looser arrangement. At low $\mathrm{pH}$, hydrogen, $\mathrm{Ca}^{2+}$, and $\mathrm{CaOH}_{2}{ }^{+}$ions are present in the solution and may be adsorbed onto the surfaces of eggshell particles forming an electrical double layer, with the

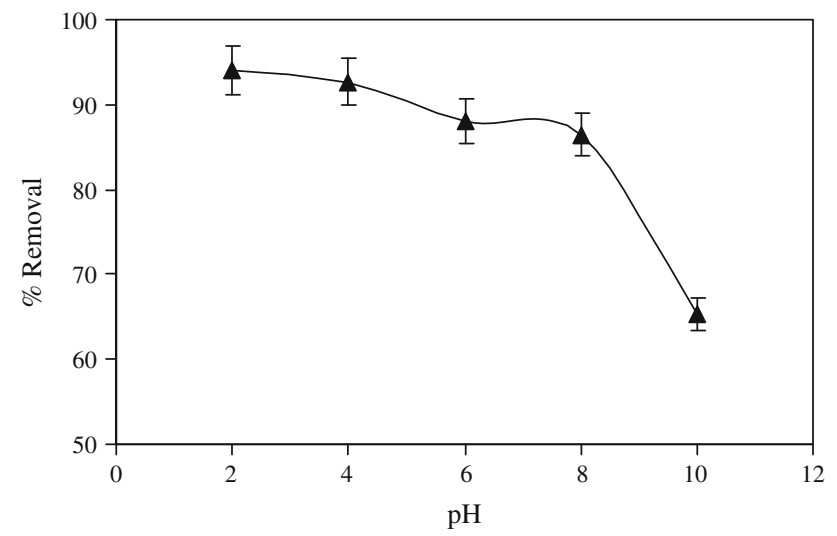

Fig. 6 Effect of $\mathrm{pH}$ on humic acid removal from peat water onto powdered eggshell (contact time $60 \mathrm{~min}$, volume $50 \mathrm{~mL}$, dosage $3 \mathrm{~g}$, particle size $75 \mu \mathrm{m}$, shaking speed $100 \mathrm{rpm}$, and $25^{\circ} \mathrm{C}$ ) surface of the eggshell particle acquiring a positive charge, as confirmed by zeta potential measurement (Fig. 2).

As previously explained, humic acid is the main components of peat water, which consist of many phenolic and carbonyl functional groups. As known, the phenolic and carbonyl functional group can be ionized in aqueous medium and may acquire a negative charge in aqueous medium, as confirmed by zeta potential measurement (Fig. 2). When humic acid is present in solution, humic acid ion will be attracted to the surface of the adsorbent by electrostatic interaction, forming a Stern OL and thus, increasing the adsorption rate of humic acid.

Meanwhile at high $\mathrm{pH}$, more hydroxyl, $\mathrm{HCO}_{3}{ }^{-}$, and $\mathrm{CO}_{3}{ }^{2-}$ ions are present in the bulk solution and are adsorbed onto eggshell surface, so the surface charge is negative (Fig. 2). These will reduce the electrostatic attraction between the eggshell particle surface and humic acid compound because of the less positive or more negative surface charges. This decreases the adsorption rate or removal of humic acid.

\section{Effect of temperature}

Effect of temperature variations to the humic acid removal by the powdered eggshell has been examined by conducting the experiments in four different temperatures: 25,45 , 55 and $65^{\circ} \mathrm{C}$. The results clearly demonstrated that variation in temperatures statistically has no significant effect on the humic acid removal from peat water (Fig. 7). These results show that although the enhancing effects of temperature on humic acid adsorption are not significant, the inhibition effects of the higher temperatures are significant and should be considered as an operational parameter in economical aspect. This observation was similar to other researches reported (Kose and Kivanc 2011). The similarity of these results may be related to adsorbent

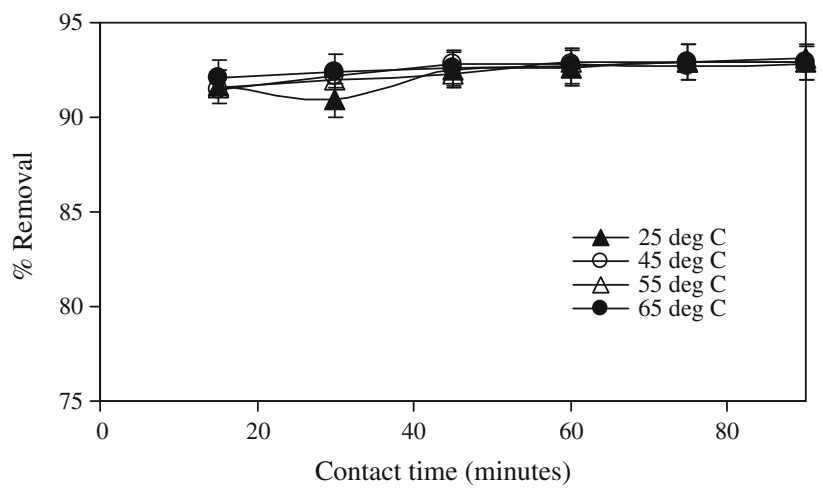

Fig. 7 Effect of temperature on humic acid removal from peat water onto powdered eggshell (volume $50 \mathrm{~mL}$, dosage $3 \mathrm{~g}, \mathrm{pH} 4.01$, particle size $75 \mu \mathrm{m}$, shaking speed $100 \mathrm{rpm})$ 
characteristics especially in term of chemical constituents (Ehrampoush et al. 2011).

\section{Adsorption isotherms}

Adsorption isotherms describe how adsorbates interact with adsorbents at constant temperature. Sorption equilibrium data provide fundamental physicochemical information for evaluating the applicability of sorption process as a unit operation. In the present investigation, the equilibrium data were analyzed with Langmuir and Freundlich isotherms.

The Langmuir isotherm theory assumes monolayer coverage of adsorbate over a homogeneous adsorbent surface. Adsorption is assumed to take place at specific homogeneous sites with the adsorbent and once an organic molecule occupies a site, no further adsorption can take place at the site. The isotherm experimental data were fitted with Langmuir model by using the following equation:

$q_{e}=\frac{q_{m} \cdot b \cdot C_{e}}{1+b \cdot C_{e}}$

where $C_{e}$ is the equilibrium concentration $(\mathrm{mg} / \mathrm{L}), q_{e}$ is amount of adsorbate adsorbed per unit weight of absorbent (mg/g), $q_{m}$ and $K_{L}$ are Langmuir constants related to maximum adsorption capacity $(\mathrm{mg} / \mathrm{g})$ and energy of adsorption $(\mathrm{L} / \mathrm{mg})$, respectively.

In Freundlich adsorption isotherm, the model assumes a heterogeneous surface with a non-uniform distribution of heat of adsorption over the surface. The isotherm experimental data were fit to the Freundlich model by using equation below:

$q_{e}=K_{f} C_{e}^{1 / n}$

where $C_{e}$ is the equilibrium concentration $(\mathrm{mg} / \mathrm{L}), q_{e}$ is amount of adsorbate adsorbed per unit weight of absorbent (mg/g), and $K_{f}$ and $n$ are Freundlich constants related to adsorption capacity and adsorption intensity, respectively. The value of $K_{f}$ itself can be used to comparable parameter for sorption capacity of an adsorbent (Daifullah et al. 2004).

The results showed that the Freundlich isotherm model fitted well to the experimental results (Fig. 8). The isotherm parameters from the models indicated that the Freundlich isotherm produces a better fitting result in terms of regression coefficient than Langmuir isotherms (Table 2). This may mean that powdered egg shell have more heterogenous types of adsorption sites (Oke et al. 2008). This result was similar to other researches reported using eggshell as adsorbent for various adsorbate (Tsai et al. 2006; Kose and Kivanc 2011; Ehrampoush et al. 2011; Oke et al. 2008). High value of $n$ indicates a strong bond between the adsorbent and the adsorbate. In our

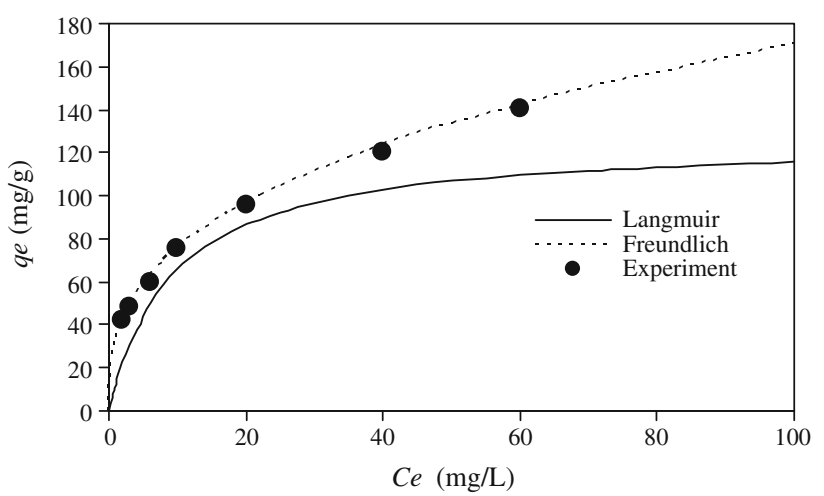

Fig. 8 Isotherm curve for humic acid removal from peat water at different powdered egg shell dosage (contact time $60 \mathrm{~min}$, volume $50 \mathrm{~mL}, \mathrm{pH} 4.01$, particle size $75 \mu \mathrm{m}$, shaking speed $100 \mathrm{rpm}$, and $25^{\circ} \mathrm{C}$ )

experiment, the value of $n$ was greater than unity (Table 2), an indication of a favorable adsorption process at high concentration of adsorbate (Ngah et al. 2008, 2011). Estimated from the Langmuir model, the maximum adsorption of humic acid from peat water on powdered egg shell is about $126.58 \mathrm{mg} / \mathrm{g}$ (Table 2).

\section{Adsorption kinetic}

In order to examine the controlling mechanism of humic acid removal process, the pseudo-first-order adsorption, the pseudo-second-order adsorption, the intra-particle diffusion, and Elovich and Boyd models were used to test the experimental data. The pseudo-first-order rate expression was evaluated with the following equation (Kamari et al. 2009; Ngah et al. 2011; Tao et al. 2010; Wang et al. 2011; Zhang and Bai 2003; Bhaumik et al. 2012; Elwakeel and Yousif 2010; Gupta and Rastogi 2008, Gupta et al. 2010; Kose and Kivanc 2011; Ehrampoush et al. 2011; Chen et al. 2010; Ugurlu et al. 2005; Okoye et al. 2010; Wang et al. 2008b; Elkady et al. 2011):

$\log \left(q_{e}-q_{t}\right)=\log q_{e}-k / 2.303 . t$

where $q_{e}$ and $q_{t}$ are the amounts of humic acid $(\mathrm{mg} / \mathrm{g})$, adsorbed on adsorbents at equilibrium and at time $t$, respectively, and $k$ is the rate constant $\left(\min ^{-1}\right)$. The value of $k$ was obtained from a slope of the linear plots of $\log$ $\left(q_{e}-q_{t}\right)$ against $t$.

The result of fitting of kinetic data for pseudo-first-order model under different adsorbent dosage is presented in Table 3. From this table, it was observed that the values of the correlation coefficients are relatively low for the different adsorbent dosages. Furthermore, the estimated values of $q_{e}$ calculated from the equation differ substantially from those measured experimentally. According to Febrianto et al. (2009), the $q_{e}$ calculated values will be 
Table 2 The Langmuir and Freundlich isoterms constants

\begin{tabular}{|c|c|c|c|c|c|}
\hline \multicolumn{3}{|c|}{ Langmuir model } & \multicolumn{3}{|c|}{ Freundlich model } \\
\hline$K_{L}(\mathrm{~L} / \mathrm{mg})$ & $q_{m}(\mathrm{mg} / \mathrm{g})$ & $R^{2}$ & $n$ & $K_{f}\left[(\mathrm{mg} / \mathrm{g})(\mathrm{L} / \mathrm{mg})^{1 / \mathrm{n}}\right]$ & $R^{2}$ \\
\hline 0.108 & 126.58 & 0.895 & 2.86 & 33.95 & 0.9996 \\
\hline
\end{tabular}

lower than the $q_{e}$ experiment values due to the presence of boundary layers or external resistances controlling at the beginning of the adsorption process. That gives confirmation that humic acid removal using eggshell did not obey the pseudo-first-order model.

The pseudo-second-order model is based on the assumption that the rate-limiting step may be chemical sorption or chemisorption involving valence forces through sharing or exchange of electrons between sorbent and sorbate. It is assumed that the sorption capacity is proportional to the number of active sites occupied on the sorbent, then the kinetic rate law can be written as follows (Kamari et al. 2009; Ngah et al. 2011; Tao et al. 2010; Wang et al. 2011; Zhang and Bai 2003; Bhaumik et al. 2012; Elwakeel and Yousif 2010; Gupta and Rastogi 2008; Gupta et al. 2010; Kose and Kivanc 2011; Ehrampoush et al. 2011; Chen et al. 2010; Ugurlu et al. 2005; Okoye et al. 2010; Wang et al. 2008b; Elkady et al. 2011):

$t / q_{t}=1 / k \cdot q_{e}^{2}+t / q_{e}$

where $q_{\mathrm{e}}$ and $q_{\mathrm{t}}$ are the amounts of organic compounds $(\mathrm{mg} / \mathrm{g})$ adsorbed on sorbents at equilibrium and at time $t$, respectively, and $k$ is the rate constant $\left(\mathrm{g} / \mathrm{mg} \mathrm{min}^{-1}\right)$. If second-order kinetics is applicable, the plot of $t / q_{t}$ against $t$ of Eq. (7) should give a linear relationship from which the constants $q_{e}$ and $k$ can be determined.

Plot of $t / q_{t}$ against $t$ for pseudo-second-order model under different adsorbent dosage are shown in Fig. 9. The $k_{2}, q_{e}$, and correlation coefficients $R^{2}$ were calculated from this plot and are given in Table 3. From this table, it was observed that the $q_{e}$ determined from the model is very close to $q_{e}$ experiment and correlation coefficient is also $>0.97$. This result suggests that the removal system could be well described by the pseudo-second-order model. Therefore, it can be said that more than one-step may be involved in the sorption processes (Ugurlu et al. 2005).

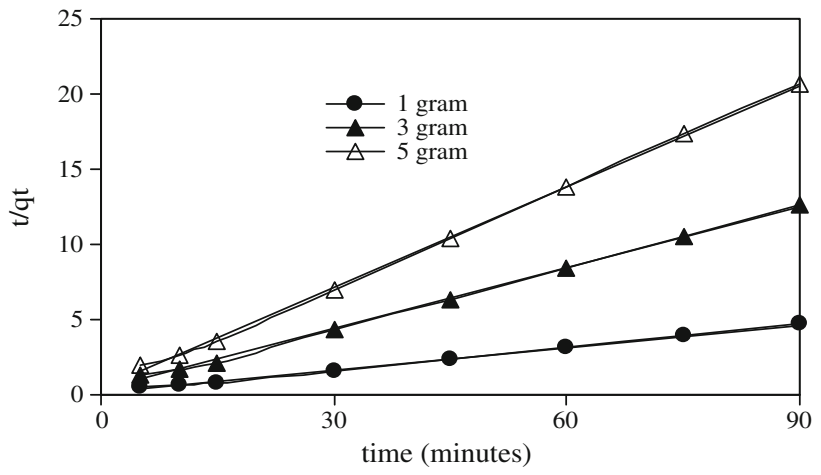

Fig. 9 Pseudo-second-order model plot for humic acid removal from peat water at different powdered egg shell dosages (volume $50 \mathrm{~mL}$, pH 4.01, particle size $75 \mu \mathrm{m}$, shaking speed $100 \mathrm{rpm}$, and $25^{\circ} \mathrm{C}$ )

The pseudo-second-order models could not identify the mechanism of removal process. Therefore, to analyze the mechanism of removal process, the intra-particle diffusion model can be used. The equation can be described as follow (Tao et al. 2010; Bhaumik et al. 2012; Elwakeel and Yousif 2010; Chen et al. 2010; Ugurlu et al. 2005; Okoye et al. 2010; Elkady et al. 2011):

$q_{t}=k \cdot t^{0.5}+C$

where $k$ and $c$ are an intra-particle diffusion rate constant $\left(\mathrm{mg} / \mathrm{g} \mathrm{min}{ }^{0.5}\right)$ and a constant, respectively. The $k$ is obtained from the slope of linier plot of $q_{t}$ vs. $t^{0.5}$. From plot of $q_{t}$ against $t^{0.5}$ (Figure not shown here), it can be seen that these plots generally have a dual nature, i.e., an initial curved portion and a final linear portion that may be explained by the fact that the initial curved portion represents boundary layer diffusion effects. The final linear portions are a result of intra-particle diffusion effects (Ugurlu et al. 2005; Jadhav and Vanjara 2004). Extrapolating the linear portion of the plot to the ordinate produces

Table 3 The pseudo-first-order and second-order kinetic parameters for humic acid removal from peat water using powdered egg shell

\begin{tabular}{|c|c|c|c|c|c|c|c|}
\hline \multirow[t]{2}{*}{ Adsorbent dosages (g) } & \multicolumn{3}{|c|}{ Pseudo-first-order } & \multicolumn{4}{|c|}{ Pseudo-second-order } \\
\hline & $k\left(\min ^{-1}\right)$ & $q_{e}, \mathrm{cal}(\mathrm{mg} / \mathrm{g})$ & $R^{2}$ & $k\left(\min ^{-1}\right)$ & $q_{e}, \mathrm{cal}(\mathrm{mg} / \mathrm{g})$ & $R^{2}$ & $q_{e}, \exp (\mathrm{mg} / \mathrm{g})$ \\
\hline 1 & 0.06 & 3.793 & 0.808 & 0.016 & 20.08 & 0.997 & 19.02 \\
\hline 3 & 0.05 & 1.315 & 0.796 & 0.101 & 5.198 & 0.999 & 7.13 \\
\hline 5 & 0.05 & 0.596 & 0.749 & 0.113 & 4.47 & 0.999 & 4.33 \\
\hline
\end{tabular}


the intercept $(C)$ which is proportional to the extent of boundary layer thickness (Jadhav and Vanjara 2004).

Referring to intra-particle diffusion plot at different adsorbent dosages, the first stage was completed within the first $15 \mathrm{~min}$ and the second stage of intra-particle diffusion control was then attained. The plot also showed that the linear lines of the second stages did not pass through the origin and this deviation from the origin or near saturation might be due to the difference in the mass transfer rate in the initial and final stages of adsorption (Mohanty et al. 2005). It confirms that intra-particle diffusion was not the only rate-limiting mechanism in the removal process (Tan et al. 2009).

The values of $k_{d 1}$ and $k_{d 2}$ as obtained from the slopes of the two straight lines are listed in Table 4 . The $k_{d}$ values were found to be generally decreased with the increasing adsorbent dosage. In order to determine the thickness of the boundary layers due to both the film diffusion and the intraparticle diffusion, the values of $C_{1}$ and $C_{2}$ are tabulated in Table 4 . The thickness of the boundary layer in the second portion that corresponds to the intra-particle diffusion $\left(C_{2}\right)$ is larger than that of the first portion that concerned the film diffusion $\left(C_{1}\right)$. Consequently, the values of the intra-particle diffusion rates $k_{\mathrm{d} 2}$ are smaller than the film diffusion rates $k_{\mathrm{d} 1}$ (Elkady et al. 2011). That gives prediction that the humic acid removal process may be controlled by the intraparticle diffusion (Elkady et al. 2011; Abd El-Latif and Ibrahim 2010).

The Elovich equation is one of the most useful models for describing chemisorption, which is given as (Okoye et al. 2010):

$q_{t}=1 / \beta \cdot \ln (\alpha \cdot \beta)+1 / \beta \cdot \ln t$

where $\alpha$ represents the initial sorption rate $(\mathrm{mg} / \mathrm{g} \min )$ and $\beta$ is related to the extent of surface coverage and activation energy for chemisorption $(\mathrm{g} / \mathrm{mg})$. The parameters $\alpha$ and $\beta$ can be computed from the slope and intercept of the linear plot of $q_{\mathrm{t}}$ versus $\ln t$. From the plot Elovich model at different adsorbent dosages, it was indicated that the $R^{2}$ values were obtained in the range of $0.605-0.872$ for the different adsorbent dosage, as seen in Table 5 .

In order to determine the actual slow step involved in the humic acid removal process, the kinetic data as obtained by the batch method were further analyzed using the Boyd model given by (Chen et al. 2010; Elkady et al. 2011):
Table 5 The Elovich and Boyd kinetic parameters for humic acid removal from peat water using powdered egg shell

\begin{tabular}{lllll}
\hline $\begin{array}{l}\text { Adsobent } \\
\text { dosage }(\mathrm{g})\end{array}$ & \multicolumn{2}{l}{ Elovich model } & & \begin{tabular}{l} 
Boyd \\
model \\
\cline { 2 - 4 }
\end{tabular} \\
\cline { 2 - 4 } & $\alpha(\mathrm{mg} / \mathrm{g} \mathrm{min})$ & $\beta(\mathrm{g} / \mathrm{mg})$ & $R^{2}$ & $R^{2}$ \\
\hline 1 & 18.267 & 0.202 & 0.872 & 0.831 \\
3 & 5.141 & 0.484 & 0.613 & 0.900 \\
5 & 3.514 & 0.202 & 0.605 & 0.821 \\
\hline
\end{tabular}

$B_{t}=-0,4977-\ln (1-F)$

$F$ represents the fraction of solute adsorbed at any time, $t$ (h), which is calculated as follows:

$F=q_{t} / q_{\alpha}$

where, $q_{\alpha}$ represents the amount sorbed $(\mathrm{mg} / \mathrm{g})$ at infinite time. The calculated $B_{\mathrm{t}}$ values were plotted against time $t$ (h). The linearity of the plots can be used to characterize the particle diffusion control mechanism (Chen et al. 2010). From plot $B_{\mathrm{t}}$ against $t$ (Figure not shown here), the plots are linear but do not pass through the origin, signifying that external mass transfer is the main rate controlling step at the initial stages (Chen et al. 2010). The values of correlation coefficient $\left(R^{2}\right)$ as obtained from these slopes are listed in Table 5.

\section{Desorption study}

One of the important characteristics of an adsorbent is its ability to be regenerated (Ngah et al. 2008). A desorption study will help to elucidate the nature of adsorption process and to reuse the adsorbent. The most common desorbing agents used to desorbs the adsorbates are $\mathrm{NaOH}, \mathrm{HCl}$, $\mathrm{HNO}_{3}, \mathrm{EDTA}, \mathrm{CaCl}_{2}$, and organic solvents such as methanol and ethanol (Ngah et al. 2008). In this study, only $\mathrm{HCl}$ was used to regenerate the adsorbent. The results of desorption experiments showed that $82 \%$ of humic acid removed from eggshell by treating with $0.1 \mathrm{M} \mathrm{HCl}$ (Figure not shown here). As the concentration of $\mathrm{HCl}$ increased, more adsorbed humic acid would be protonated. The high desorption percentage of humic acid with increase of $\mathrm{HCl}$ concentration was attributed to the more repulsive electrostatic interaction between humic acid protonated and adsorbent.
Table 4 The intra-particle diffusion model parameters for the humic acid removal from peat water using powdered egg shell

\begin{tabular}{lllllll}
\hline $\begin{array}{l}\text { Adsorbent } \\
\text { dosage }(\mathrm{g})\end{array}$ & $\begin{array}{l}k_{d 1} \\
\left(\mathrm{mg} / \mathrm{g} \mathrm{min} \mathrm{min}^{0.5}\right)\end{array}$ & $C_{l}$ & $R_{1}^{2}$ & $\begin{array}{l}k_{d 2} \\
\left(\mathrm{mg} / \mathrm{g} \mathrm{min} \mathrm{min}^{0.5}\right.\end{array}$ & $C_{2}$ & $R_{2}^{2}$ \\
\hline 1 & 6.392 & -5.441 & 0.983 & 0.0623 & 18.6 & 0.693 \\
3 & 1.976 & -0.650 & 0.995 & 0.0389 & 6.8125 & 0.928 \\
5 & 1.110 & 0.057 & 0.9686 & 0.0024 & 4.3117 & 0.3014 \\
\hline
\end{tabular}


Table 6 Comparison of adsorption capacity of various adsorbent for humic acid removal

\begin{tabular}{|c|c|c|c|c|c|c|}
\hline Materials & Adsorbate & $q_{m}(\mathrm{mg} / \mathrm{g})$ & Concentration range $(\mathrm{mg} / \mathrm{L})$ & $\mathrm{pH}$ & Contact time & Reference \\
\hline Shorea dasyphylla sawdust & Humic acid & 68.4 & $10-80$ & 2 & $30 \mathrm{~min}$ & Kamari et al. 2009 \\
\hline Chitosan-PET & Humic acid & 0.407 & $10-60$ & 6.5 & $60 \mathrm{~h}$ & Zhang and Bai 2003 \\
\hline Rice husk activated carbon & Humic acid & 45.4 & $20-150$ & 10 & - & Daifullah et al. 2004 \\
\hline Fly ash & Humic acid & 36.0 & $10-100$ & 5 & $170 \mathrm{~h}$ & Wang et al. $2008 \mathrm{~b}$ \\
\hline Eggshell & Peat water & 126.58 & - & 4.01 & $60 \mathrm{~min}$ & This study \\
\hline Chitosan- $\mathrm{H}_{2} \mathrm{SO}_{4}$ beads (at $300 \mathrm{~K}$ ) & Humic acid & 377.4 & $0-70$ & - & $60 \mathrm{~min}$ & Ngah et al. 2011 \\
\hline Activated carbon & Humic acid & 52.4 & $0-200$ & 7 & $24 \mathrm{~h}$ & Tao et al. 2010 \\
\hline SBA-15 & Humic acid & 8.5 & $0-200$ & 7 & $24 \mathrm{~h}$ & Tao et al. 2010 \\
\hline APTS-SBA-15-5 \% & Humic acid & 72.5 & $0-200$ & 7 & $24 \mathrm{~h}$ & Tao et al. 2010 \\
\hline APTS-SBA-15-10 \% & Humic acid & 117.6 & $0-200$ & 7 & $24 \mathrm{~h}$ & Tao et al. 2010 \\
\hline ATP-PANI (at $25^{\circ} \mathrm{C}$ ) & Humic acid & 52.91 & $5-60$ & 5 & $24 \mathrm{~h}$ & Wang et al. 2011 \\
\hline
\end{tabular}

Comparison of humic acid removal with other adsorbents reported in literature

It is also important to compare the value of maximum adsorption capacity obtained from this study with values from other reported adsorbents, since this will suggest the effectiveness of eggshells as a potential low cost adsorbent for humic acid removal. Although the Freundlich adsorption constants are difficult to compare with Langmuir adsorption isotherm, the maximum capacity, $q_{m}$, is comparable with the value in literature. The values of adsorption capacity for humic acid removal using some adsorbents are shown in Table 6.

The experimental data of the present investigations are higher than other reported values. The adsorption capacity varies and it depends on the characteristics of the individual adsorbent, the extent of surface/surface modification, the initial concentration of the adsorbate (Mousavi and Seyedi 2011), range of molecular size fraction of adsorbate, and degree of ionization per unit weight of the adsorbate (García et al. 1998).

\section{Conclusion}

The main aim of this study was to investigate the possibility powdered eggshell used as an adsorbent material. The results from this work showed that the process apparently reach equilibrium in nearly $60 \mathrm{~min}$ of contact time. The $\mathrm{pH}$ plays an important role in the humic acid removal from peat water and showed that the maximum removal occurred at $\mathrm{pH}$ 2. In addition, the temperature has no significant effect on the humic acid removal. The optimum dosage of powdered eggshell was $5 \mathrm{~g}$. The adsorption isotherm data tends to fit with the Freundlich model. The adsorption capacity was obtained around $126.58 \mathrm{mg} / \mathrm{g}$ at $\mathrm{pH} 4.01$, estimated from the Langmuir model. The kinetic experimental data were strongly correlated with the pseudo-second-order kinetic model with a rate constant in the range of $0.016-0.112 \mathrm{~g} \mathrm{mg}^{-1} \mathrm{~min}^{-1}$, while both the intra-particle diffusion and Boyd kinetic model indicated that intra-particle diffusion was the main rate determining step in humic acid removal process. Comparative results revealed that eggshell provides a better adsorbent property in comparison with other adsorbents. The results of this study suggest that powdered eggshell, with low cost and abundant availability in environment, have a potential of being used as an adsorbent for humic acid removal from peat water and could be used in water treatment.

Acknowledgments The authors are very grateful to authorities of the Pasar Balubur, Bandung, Indonesia for kindly providing the eggshell samples for this research study.

\section{References}

Abd El-Latif MM, Ibrahim AM (2010) Removal of reactive dye from aqueous solutions by adsorption onto activated carbons prepared from oak sawdust. Des Water Treat 20:102-113

Albers CN, Banta GT, Hansen PE, Jacobsen OS (2008) Effect of different of humic substances on the fate of diuron and its main metabolite 3,4-dichloroaniline in soil. Environ Sci Technol 42:8687-8691

Bhaumik R, Mondal NK, Das B, Roy P, Pal KC, Das C, Banerjee A, Datta JK (2012) Eggshell powder as an adsorbent for removal of fluoride from aqueous solution: equilibrium, kinetic and thermodynamic studies. E-J Chem 9(3):1457-1480

Carvalho J, Araujo J, Castro F (2011) Alternative low-cost adsorbent for water and wastewater decontamination derived from eggshell waste: an overview. Waste Biomass Valor 2:157-167

Chen DZ, Zhang JX, Chen JM (2010) Adsorption of methyl tert-butyl ether using granular activated carbon: equilibrium and kinetic analysis. Int J Environ Sci Technol 7(2):235-242

Daifullah AAM, Girgis BS, Gad HMH (2004) A study of the factors affecting the removal of humic acid by activated carbon prepared from biomass material. Colloids Surf A 235:1-10 
Ehrampoush MH, Ghanizadeh G, Ghaneian MT (2011) Equilibrium and kinetics study of reactive Red 123 dye removal from aqueous solution by adsorption on eggshell. Iran J Environ Health Sci Eng 8(2):101-108

Elkady MF, Ibrahim AM, Abd El-Latif MM (2011) Assessment of the adsorption kinetics, equilibrium and thermodynamic for the potential removal of reactive red dye using eggshell biocomposite beads. Desalination 278:412-423

Elwakeel KZ, Yousif AM (2010) Adsorption of Malathion on thermally treated egg shell material. Water Sci Technol 61(4):1035-1041

Febrianto J, Natasia AK, Sunarso J, Ju YH, Indraswati N, Ismadji S (2009) Equilibrium and kinetic studies in adsorption of heavy metals using biosorbents: a summary of recent studies. J Hazard Mater 162:616-645

García MAF, Utrilla JR, Toledo IB, Castilla CM (1998) Adsorption of humic substances on activated carbon from aqueous solutions and their effect on the removal of $\mathrm{Cr}(\mathrm{III})$ ions. Langmuir 14:1880-1886

Gezici O, Kara H, Ersoz M, Abali Y (2005) The sorption behaviour of nickel-insolubilized humic acid system in a column arrangement. J Colloid Interface Sci 292:381-391

Ghernaout D, Ghernaout B, Saibaa A, Boucherita A, Kellil A (2009) Removal of humic acids by continuous electromagnetic treatment followed by electrocoagulation in batch using aluminium electrodes. Desalination 239:295-308

Gupta VK, Rastogi A (2008) Equilibrium and kinetic modeling of cadmium (II) biosorption by nonliving algal biomass Oedogonium sp. from aqueous phase. J Hazard Mater 153:759-766

Gupta VK, Carrott PJM, Carrott MMLR, Suhas (2009) Low-cost adsorbents: Growing approach to wastewater treatment-a review. Critical Rev Environ Sci Technol 39:783-842

Gupta VK, Rastogi A, Nayak A (2010) Adsorption studies on the removal of hexavalent chromium from aqueous solution using a low cost fertilizer industry waste material. J Colloid Interface Sci 342:135-141

Jadhav DN, Vanjara AK (2004) Adsorption kinetics study: removal of dyestuff effluent using sawdust, polymerized sawdust and sawdust carbon-II. Indian J Chem Technol 11:42-50

Kamari A, Ngah WSW, Wong LW (2009) Shorea dasyphylla sawdust for humic acid adsorption. Eur J Wood Prod 67:417-426

Katsoufidou KS, Sioutopoulos DC, Yiantsios SG, Karabelas AJ (2010) UF membrane fouling by mixtures of humic acids and sodium alginate: fouling mechanisms and reversibility. Desalination 264:220-227

Kose TE, Kivanc B (2011) Adsorption of phosphate from aqueous solutions using calcined waste eggshell. Chem Eng J 178:34-39

Labidi NS, Djebaili A (2008) Studies of the mechanism of polyvinyl alcohol adsorption on the calcite/water interface in the presence of sodium oleate. J Minerals Mater Charac Eng 7(2):147-161

Mohanty K, Das D, Biswas MN (2005) Adsorption of phenol from aqueous solutions using activated carbons prepared from Tectona grandis sawdust by $\mathrm{ZnCl}_{2}$ activation. Chem Eng J 115: $121-131$

Mousavi HZ, Seyedi SR (2011) Nettle ash as a low cost adsorbent for the removal of nickel and cadmium from wastewater. Int $\mathrm{J}$ Environ Sci Tech 8(1):195-202
Muarakami FS, Rodrigues PO (2007) Physicochemical study of $\mathrm{CaCO}_{3}$ from egg shells. Cienc Technol Aliment Camp 27(3): 658-662

Ngah WSW, Hanafiah MAKM, Yong SS (2008) Adsorption of humic acid from aqueous solutions on crosslinked chitosan-epichlorohydrin beads: kinetics and isotherm studies. Colloids Surf B 65:18-24

Ngah WSW, Fatinathan S, Yosop NA (2011) Isotherm and kinetic studies on the adsorption of humic acid onto chitosan- $\mathrm{H}_{2} \mathrm{SO}_{4}$ beads. Desalination 272:293-300

Oke IA, Olarinoye NO, Adewusi SRA (2008) Adsorption kinetics for arsenic removal from aqueous solutions by untreated powdered eggshell. Adsorption 14:73-83

Okoye AI, Ejikeme PM, Onukwuli OD (2010) Lead removal from wastewater using fluted pumkin seed shell activated carbon: adsorption modeling and kinetics. Int $\mathrm{J}$ Environ Sci 7(4): 793-800

Sonea D, Pode R, Manea F, Ratiu C, Lazau C, Grozescu I, Burtica G (2010) The comparative assessment of photolysis, sorption and photocatalysis processes to humic acids removal from water. Chem Bull "Politehnica" Univ (Timisoara) 55(69):148-151

Tan IAW, Ahmad AL, Hameed BH (2009) Adsorption isotherms, kinetics, thermodynamics and desorption studies of 2,4,6trichlorophenol on oil palm empty fruit bunch-based activated carbon. J Hazard Mater 164:473-482

Tao Q, Xu Z, Wang J, Liu F, Wan H, Zheng S (2010) Adsorption of humic acid to aminopropyl functionalized SBA-15. Micropor Mesopor Mater 131:177-185

Tsai WT, Yang JM, Lai CW, Cheng YH, Lin CC, Yeh CW (2006) Characterization and adsorption properties of eggshells and eggshells membrane. Bioresource Technol 97:488-493

Ugurlu M, Gurses A, Yalcin M, Dogar C (2005) Removal of phenolic and lignin compounds from bleached kraft mill effluent by fly ash and sepiolite. Adsorption 11:87-97

Uygunera CS, Suphandaga SA, Kercb A, Bekbolet M (2007) Evaluation of adsorption and coagulation characteristics of humic acids preceded by alternative advanced oxidation techniques. Desalination 210:183-193

Wang S, Sun X, Liu X, Gong W, Gao B, Bao N (2008a) Chitosan hydrogel beads for fulvic acid adsorption: behaviours and mechanism. Chem Eng J 142:239-247

Wang S, Terdkiatburana T, Tade MO (2008b) Single and coadsorption of heavy metals and humic acid on fly ash. Sep Purif Technol 58:353-358

Wang J, Han X, Ma H, Ji Y, Bi L (2011) Adsorptive removal of humic acid from aqueous solution on polyaniline/attapulgite composite. Chem Eng J 173:171-177

Zhang X, Bai R (2003) Mechanism and kinetics of humic acid adsorption onto chitosan-coated granules. J Colloid Interface Sci 264:30-38

Zulfikar MA, Mariske ED, Djajanti SD (2012) Adsorption of lignosulfonate compound using powdered eggshells. Songklanakarin J Sci Technol 34(3):309-316 